\title{
A 15-Year Review of Ocular Manifestations of Autoimmune Inflammatory Disorders in a University Hospital
}

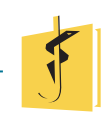

\author{
Gerald B. Natanauan, $M D^{\prime}$; Julie T. Li-Yu, MD, $M S P H^{\prime}$; \\ Jessica C. Daza-Robes, MD² ; Jessica Marie R. Abaño, MD²
}

\begin{abstract}
Background: Autoimmune diseases represent a significant health burden for $3 \%$ to $9 \%$ of the general population, and rheumatology, perhaps more than any other medical subspecialty, encompasses a broad array of such diseases that affect a wide range of organ systems including the eye. It serves as a sensitive barometer of autoimmune phenomena in many of the rheumatic diseases.
\end{abstract}

Objective: The study determined the various ocular manifestations of all autoimmune inflammatory disorders at the University of Santo Tomas Hospital, Section of Rheumatology and the Department of Ophthalmology from 2003 to 2018.

Methodology: A retrospective cohort study was done involving chart review of patients from both private division and clinical division. Sex, age, duration of disease, medications given, and ocular manifestations were determined. Statistical analysis included frequencies, percentages, and logistic regression analysis.

Results: Sixty-seven patients were included in the study. Of these, 58.2\% (39/67) had ocular manifestations secondary to an established

Gerald B. Natanauan, MD iroirald@gmail.com

1. Section of Rheumatology, Clinical Immunology and Osteoporosis, Department of Internal Medicine, University of Santo Tomas Hospital, Manila

2. Department of Ophthalmology, University of Santo Tomas Hospital, Manila autoimmune disease. It was found out that $58.97 \%$ (23/39) had Vogt-Koyanagi-Harada syndrome. Other autoimmune diseases with ophthalmologic manifestations were systemic lupus erythematosus at $12.8 \%(5 / 39)$, ankylosing spondylitis at $10.25 \%$ (4/39), rheumatoid arthritis and Behcet's syndrome at $5.12 \%(2 / 39)$, and granulomatosis with polyangiitis, scleroderma and psoriatic arthritis at $2.56 \%(1 / 39)$.

Conclusion: In this population, the frequency of ocular manifestations of autoimmune diseases remained low with anterior uveitis as the most common. Close coordination between specialties is very important in the course of treatment and management to lessen its complications and related morbidity.

Key words: Ocular manifestations, autoimmune inflammatory disorders

\section{INTRODUCTION}

Autoimmune diseases represent a significant health burden for $3 \%$ to $9 \%$ of the general population, and rheumatology, perhaps more than any other medical subspecialty, encompasses a broad array of such diseases that affect a wide range of organ systems. [1] The eye serves as a sensitive barometer for the onset of or reactivation of autoimmune phenomena in many rheumatic diseases. Understanding the ocular manifestations of rheumatic diseases is critically important for rheumatologists. [2] Many autoimmune diseases are well associated with specific types of 
inflammatory ocular manifestations. For example, keratoconjunctivitis sicca is the most frequent ocular complication in Sjogren's disease and rheumatoid arthritis, while acute anterior uveitis is the primary manifestation of ankylosing spondylitis. These ocular manifestations range widely in severity from causing mild discomfort to a complete loss of vision. [3]

The rheumatologist, in coordination with the ophthalmologist, can play a key role in detecting and managing eye involvement in these patients to save this important organ. Understanding the varied manifestations of eye disease will permit the rheumatologist to better evaluate the activity of rheumatic disease. [1]

The study aimed at determining the various ocular manifestations of all autoimmune inflammatory disorders co-managed by the hospital's Section of Adult Rheumatology and the Department of Ophthalmology from 2003 to 2018. More specifically, it determined the eye conditions that occur in each autoimmune disease and the duration from onset of ocular manifestations to expression of rheumatic disease, analyzed the association of autoimmune inflammatory disease activity and duration of disease with ocular symptoms and discussed the treatment response of various ocular manifestations of autoimmune inflammatory disorders.

\section{METHODOLOGY}

This was a single-center retrospective cohort study of patients. The patient records from January 2003 to December 2018 were collected. All Filipino adult patients aged more than or equal to 18 years old seen in the hospital's Section of Adult Rheumatology and Department of Ophthalmology diagnosed with autoimmune diseases with ocular manifestations were included in the study. Those diagnosed with chronic metabolic diseases and infection-related were not included. The sample size determined was 108 based on an estimate to get the best representative population similar to other studies.

Approval from the University of Santo Tomas Hospital - Research Ethics Committee (USTH-REC) was obtained prior to data collection. Permission from the USTH Medical Director, Data Privacy Officer, Head of the Ambulatory Care Services and the attending rheumatologist and ophthalmologist were obtained as well.
Demographic data were gathered including gender and age, disease duration, laboratory features (such as complete blood count, platelet count, etc.), ocular manifestations, and treatment modalities. These variables were correlated to determine health-related significance or impact.

Descriptive statistics including mean, standard deviation, median, lower, and upper quartiles were calculated for the examined variables. The prevalence of varied ocular manifestations with autoimmune diseases was determined by calculating the percentage of patients in a base of 100. The relationship between clinical variables (age, sex, duration of autoimmune disease) with that of ocular manifestations was assessed by performing the logistic regression analysis (multivariate analysis).

\section{RESULTS}

Of all the patients seen in the clinic illustrated in Table 1, 58.2\% (39/67) had ocular manifestations which were secondary to an established autoimmune disease while the remaining $41.8 \%$ (28/67) were unclassified. Overall, the average age of included patients was $40.4 \pm 15.9$ (18-81). Majority of the patients were females at $80.59 \%(54 / 67)$ and all of them came from the Asian race.

Table 2 shows that $58.97 \%$ (23/39) had Vogt-Koyanagi-Harada syndrome (VKH). The other autoimmune diseases with ophthalmologic manifestations were systemic lupus erythematosus (SLE) at $12.8 \%(5 / 39)$, ankylosing spondylitis (AS) at $10.25 \%$ (4/39), rheumatoid arthritis (RA) and Behcet's at $5.12 \%(2 / 39)$, and granulomatosis with polyangiitis (GPA), scleroderma and psoriatic arthritis $(\mathrm{PsA})$ at $2.56 \%(1 / 39)$. The mean age of

Table 1. Study population demographics

\begin{tabular}{lcc}
\hline & $\begin{array}{c}\text { ALL patients } \\
\text { seen in the } \\
\text { clinic }\end{array}$ & $\begin{array}{c}\text { Diagnosed autoimmune } \\
\text { disease with ophthalmologic } \\
\text { manifestations }\end{array}$ \\
\hline$N(\%)$ & $67(100)$ & $39(58.2)$ \\
$\begin{array}{l}\text { Average age } \\
\text { (SD) }\end{array}$ & $\begin{array}{c}40.4 \pm 15.9 \\
(18-81)\end{array}$ & $35 \pm 13(20-51)$ \\
Gender & & \\
$\%$ Male & $13(19.40)$ & $7(10.4)$ \\
$\%$ Female & $54(80.59)$ & $32(47.7)$ \\
Race & & $39(100)$ \\
$\%$ Asian & $67(100)$ & 0 \\
$\%$ Caucasian & 0 &
\end{tabular}


Table 2. Total number of patients diagnosed with autoimmune diseases with ophthalmologic manifestations ( $\mathrm{n}=39$ )

\begin{tabular}{lcccc}
\hline \multicolumn{1}{c}{ Autoimmune Diagnosis } & $\begin{array}{c}\text { Total No. of } \\
\text { Patients } \\
\text { N (\%) }\end{array}$ & $\begin{array}{c}\text { Male } \\
\text { N (\%) }\end{array}$ & $\begin{array}{c}\text { Female } \\
\text { N (\%) }\end{array}$ & $\begin{array}{c}\text { Age } \\
\text { (Mean } \pm \text { SD) }\end{array}$ \\
\hline Vogt-Koyanagi-Harada Syndrome (VKH) & $23(58.97)$ & $3(13.04)$ & $20(86.95)$ & $43 \pm 13(20-74)$ \\
Systemic Lupus Erythematosus (SLE) & $5(12.8)$ & $0(0)$ & $5(100)$ & $49 \pm 19(29-81)$ \\
Ankylosing Spondylitis (AS) & $4(10.25)$ & $2(50)$ & $2(50)$ & $41 \pm 13(25-56)$ \\
Rheumatoid Arthritis (RA) & $2(5.12)$ & $1(50)$ & $1(50)$ & $24 \pm 3(22-27)$ \\
Behcet's Syndrome & $2(5.12)$ & $1(50)$ & $1(50)$ & $26 \pm 5(22-30)$ \\
Granulomatosis with polyangiitis (GPA) & $1(2.56)$ & $0(0)$ & $1(100)$ & 23 \\
Scleroderma & $1(2.56)$ & $0(0)$ & $1(100)$ & 51 \\
Psoriatic Arthritis (PsA) & $1(2.56)$ & $0(0)$ & $1(100)$ & 30 \\
\hline
\end{tabular}

patients with $\mathrm{VKH}$ was $43 \pm 13$ (20-74) while those with SLE were at $49 \pm 19$ (29-81).

Of the 39 patients who had ocular manifestations secondary to an established autoimmune disease, 15 of them had specific ophthalmic diagnoses as shown in Figure 1. The most common ocular manifestation was anterior uveitis at $40 \%(6 / 15)$ followed by panuveitis at $20 \%(3 / 15)$, scleritis and anterior ischemic optic neuropathy at $13.33 \%(2 / 15)$ and intermediate uveitis and keratitis at $6.66 \%(1 / 15)$. AS on the other hand presented with the greatest number of ocular manifestations at $26.66 \%$ (4/15) followed by VKH and RA at 20\% (3/15), Behcet's syndrome at $13.33 \%(2 / 15)$, and SLE and PsA at $6.66 \%(1 / 15)$.

The highest mean dose of prednisone use for the initial treatment of autoimmune disease was observed among the RA group at a mean dose of $40 \mathrm{mg}$, followed by VKH (36.5 mg), AS (20 $\mathrm{mg})$, SLE (15 mg), and Behcet's $(10 \mathrm{mg})$. For methotrexate use, AS had the highest mean dose at $20 \mathrm{mg}$ followed by VKH (13 mg) and RA at 12.5 $\mathrm{mg}$ dose. For azathioprine use, Behcet's had the highest mean dose at $150 \mathrm{mg}$, followed by $\mathrm{VKH}$ at $100 \mathrm{mg}$ and SLE at $50 \mathrm{mg}$. One patient made use of mycophenolate mofetil in the VKH group, cyclophosphamide in the RA group, golimumab

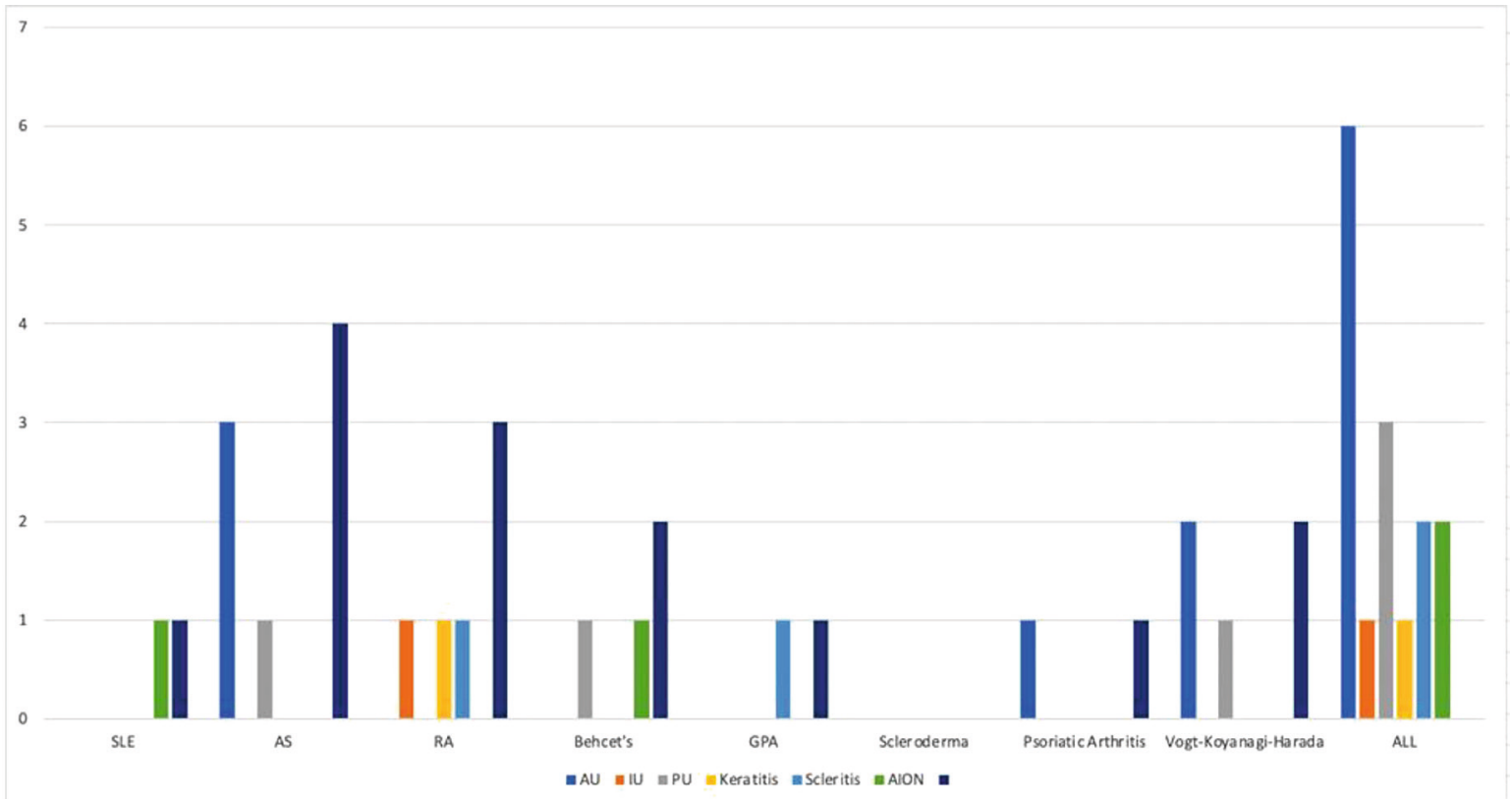

$\mathrm{AU}=$ anterior uveitis, $\mathrm{IU}=$ intermediate uveitis, $\mathrm{PU}=$ =panuveitis, $\mathrm{AION}=$ anterior ischemic optic neuropathy, $\mathrm{SLE}=$ systemic lupus erythematosus, $R A=$ rheumatoid arthritis, $A S=$ ankylosing spondylitis, GPA=granulomatosis with polyangiitis

Figure 1. Specific ophthalmic diagnoses associated with autoimmune diseases $(n=15)$ 
Table 3. Mean Disease Duration, Treatment Duration and Initial Treatment Doses

\begin{tabular}{|c|c|c|c|c|c|c|}
\hline $\begin{array}{l}\text { Autoimmune } \\
\text { Diagnosis }\end{array}$ & $\begin{array}{c}\text { Disease } \\
\text { Duration in } \\
\text { Months } \\
\text { (Mean士SD) }\end{array}$ & $\begin{array}{c}\text { Treatment } \\
\text { Duration in } \\
\text { Months } \\
\text { (Mean士SD) }\end{array}$ & $\begin{array}{l}\text { Prednisone } \\
\text { in } \mathbf{~ m g} \\
\text { (Mean) }\end{array}$ & $\begin{array}{l}\text { Methotrex- } \\
\text { atein mg } \\
\text { (Mean) }\end{array}$ & $\begin{array}{l}\text { Mycopheno- } \\
\text { latein mg } \\
\text { (Mean) }\end{array}$ & $\begin{array}{l}\text { Azathiopri- } \\
\text { nein mg } \\
\text { (Mean) }\end{array}$ \\
\hline $\begin{array}{l}\text { Vogt-Koyanagi- } \\
\text { Harada } \\
\text { Syndrome (VKH) }\end{array}$ & $29 \pm 43$ & $19 \pm 36$ & 36.5 & 13.05 & 1000 & 100 \\
\hline $\begin{array}{l}\text { Systemic Lupus } \\
\text { Erythematosus } \\
\text { (SLE) }\end{array}$ & $29 \pm 41$ & $7 \pm 14$ & 15 & - & - & 50 \\
\hline $\begin{array}{l}\text { Ankylosing } \\
\text { Spondylitis (AS) }\end{array}$ & $12 \pm 14.6$ & $37 \pm 9$ & 20 & 20 & - & - \\
\hline $\begin{array}{l}\text { Rheumatoid } \\
\text { Arthritis (RA) }\end{array}$ & $26 \pm 21.5$ & $38 \pm 33$ & 40 & 12.5 & - & - \\
\hline $\begin{array}{l}\text { Behcet's } \\
\text { Syndrome }\end{array}$ & $8 \pm 4$ & $8 \pm 4$ & 10 & - & - & 150 \\
\hline $\begin{array}{l}\text { Granulomatosis } \\
\text { with polyangiitis } \\
\text { (GPA) }\end{array}$ & 12 & 36 & - & - & - & - \\
\hline Scleroderma & 0 & 0 & - & - & - & - \\
\hline $\begin{array}{l}\text { Psoriatic Arthritis } \\
\text { (PsA) }\end{array}$ & 0 & 0 & - & - & - & - \\
\hline
\end{tabular}

\begin{tabular}{lcccc} 
& Coefficient & SE & t-value & p-value \\
\hline Constant & 18.14 & & & \\
Age & -0.0175 & 0.4246 & -0.0413 & $0.9673^{\text {ns }}$ \\
Prednisone Dose & 0.6843 & 0.3209 & 2.132 & $0.0399^{*}$ \\
\hline
\end{tabular}

Adjusted $R$ Square $=6.56 \%$; Overall $p$-value $(p=.1116) ; n=39$

* Significant if $p$-value is less than or equal to the 0.05 level of significance.

Figure 2. Multiple Regression Analysis

and secukinumab in the AS group and rituximab in the GPA group.

Table 3 shows that SLE and VKH had the longest disease duration (in months) from the time of initial disease manifestation including the occurrence of ophthalmologic signs and symptoms until the last noted clinic follow-up at 29 months. This was followed by RA at 26 months, AS and GPA at 12 months, Behcet's at 8 months, and scleroderma and PsA at less than 1 month. On the other hand, RA had the longest treatment duration followed by AS.

Using multiple regression analysis as shown in Figure 2 to assess between the independent variables (age and prednisone dose) and dependent variable (disease duration), age is not a significant factor for the duration of disease $(p=.9673)$. On the other hand, the resulting p-value of 0.0399 denotes that the prednisone dose has a significant effect on the duration of disease. Specifically, the resulting coefficient of 0.6843 implies that every half a month increase in the duration of disease is associated with 1 unit $(\mathrm{mg})$ increase in prednisone dose. Overall, the model obtained a p-value of 0.1116 and very little adjusted $r$ square of $6.56 \%$ denotes that as a whole model, taking age and prednisone together, it cannot significantly affect disease duration.

\section{DISCUSSION}

In an average of 4,513 rheumatic disease patients seen per year in this tertiary hospital, 67 patients presented with autoimmune-related ocular manifestations between 2003 and 2018 at $0.1 \%$ 
(67/67,695). In comparison, a US-based study of 1,225 patients found the same low frequency of inflammatory ocular manifestations in all patients with qualifying autoimmune disease at $2 \%$ (25/1,225 patients) between 2008 and 2013. The rarity of these conditions can also be attributed to the difficulty and intricacy of its diagnosis and management.

The findings in this study are also consistent with other literature that anterior uveitis is the most common ocular manifestation found in these groups of patients. Furthermore, from an epidemiologic perspective, anterior uveitis is more common than posterior or intermediate uveitis. The most common systemic illness associated with uveitis is ankylosing spondylitis, which is found in most North American practices.[1] In this study, among the included AS patients, three had presented with anterior uveitis as well. This relationship is established by a genomewide screen for susceptibility genes for acute anterior uveitis, which identified loci that both predispose to and not to susceptibility to AS. [1]

Clinicians can be aided to target appropriate therapy with the common ocular manifestations per rheumatic disease in consideration that necessitates close coordination between specialties, especially ophthalmology and rheumatology.[2] In this study, Behcet's presented with uveitis and retinal pathology, GPA or Wegener's granulomatosis presented with scleritis, scleroderma with dry eyes, RA with scleritis and uveitis, and SLE with neuro-ophthalmic lesions. These ocular manifestations can present at any time during the course of disease, most especially when the autoimmune disease is poorly controlled by antiinflammatory medications.

The chronic and unpredictable nature of SLE, RA, and vasculitis were some of the factors considered in the long disease duration of these autoimmune diseases. Likewise, the severe retinopathy in this group of SLE patients is typically associated with active systemic disease and central nervous system lupus in particular.

Levitt, et al. [3] reported that per disease, the proportion of ophthalmic manifestations was highest in granulomatosis with polyangiitis (GPA, formerly known as Wegener's granulomatosis, 1 out of 8 total GPA patients); After GPA, the proportion of inflammatory eye disease was highest in sarcoid (9/198 patients), GCA (2/68 patients), and rheumatoid arthritis (11/576 patients). This is in contrast to this study in which AS presented with the greatest number of ocular manifestations.

The longer the disease duration more likely it is to maintain patients on immunosuppressive therapies including the use of corticosteroids. In this view, awareness on the side effects of medications used is very important as these may also aggravate any existing pathologic conditions. Likewise, rheumatologists need to be especially aware of the potential for antimalarial agents to cause retinal toxicity like hydroxychloroquine (HCQ). Optical coherence tomography (OCT) studies now show that retinal toxicity is roughly $7.5 \%$ among persons taking $\mathrm{HCQ}$.

In this study, the determination of the duration of ocular manifestation towards expression of rheumatic disease became difficult due to lack of needed data for full analysis. However, in most of the cases, it was seen that higher the disease activity is, more likely it is that the duration of disease will be longer if appropriate treatment will not be given on time such as high-dose steroids for both ocular and extraocular manifestations. This will also answer the likely relationship between an autoimmune inflammatory disorder and ocular manifestation in which the more controlled the disease activity is the less likely that ocular flares will happen. As to treatment response, RA had the highest requirement for prednisone use reflecting its aggressive and chronic nature; AS for methotrexate, and Behcet's for azathioprine use.

The treatment management conveyed in this paradigm was based on a shared decision making between the physician and patient. It should be noted that the primary goal was to control the disease activity of autoimmune disease in order to address and prevent further and future complications. From systemic steroids to other immunosuppressive therapies including biologics, the treatment depended on multiple factors such as severity, location within the eye, patient preference, and specific diagnosis. The best treatment response for the ophthalmologic problem was the resolution of inflammation, regaining of eye function and control of the autoimmune disease itself.

Prednisone use affects both the disease activity and duration of autoimmune disease. The higher the dosage of anti-inflammatory medication, the faster and better is the control of disease activity that will likely shorten the duration of disease. The determinant therefore is still the disease activity itself 
triggered by known factors that will determine how much prednisone will be given for optimum control towards disease remission.

The eye is a complex structure which reflects dynamic processes in the body. Treatment of ocular inflammation requires careful collaboration between specialists.

\section{CONCLUSION}

In this population, the ocular manifestations of autoimmune diseases remained at a low frequency similar to other studies. The importance of early recognition is significant for proper treatment and management of this condition to lessen any related morbidity. It should be highlighted that despite the low frequency of these autoimmunerelated manifestations, great care and focus for these groups of patients remain vital as the eye in itself can be a window of any ongoing systemic or inflammatory disease. Hence, close coordination between specialists is core in the success of disease management.

We recognize the limitations of this study such that it is greatly limited by the retrospective nature which was largely dependent on what was reported on the patient's medical records. Hence, some data were missing from the records leading to exclusion of some patients. A prospective study wherein all possible risk factors are identified and monitored is recommended to determine the likelihood of each risk factor to be present in the study interest group. Finally, the small number of patients included in the study may not be the best representation of the actual population of patients. A study including a bigger population with more inclusive years in the future is recommended.

\section{Disclosure}

The researchers claim no conflict of interest. 


\section{REFERENCES}

1. Firestein G, Budd R, Gabriel S, et al. Kelly \& Firestein's Textbook of Rheumatology. 10th ed. Elsevier; 2017.

2. Hamideh F, Prete PE. Ophthalmologic manifestations of rheumatic diseases. Semin Arthritis Rheum [Internet]. 2001;30(4):217-41. Available from: http://dx.doi. org/10.1053/sarh.2001.16639

3. Levitt AE, McManus KT, McClellan AL, Davis JL, Goldhardt R, Galor A. Ocular inflammation in the setting of concomitant systemic autoimmune conditions in an older male population. Cornea [Internet]. 2015;34(7):762-7. Available from: http://dx.doi.org/10.1097/ICO.0000000000000437

4. Akinsoji E, Goldhardt R, Galor A. A glimpse into uveitis in the aging eye: Pathophysiology, clinical presentation and treatment considerations. Drugs \& Aging [Internet]. 2018;35(5):399-408. Available from: http://dx.doi. org/10.1007/s40266-018-0545-3

5. Murray Pl, Rauz S. The eye and inflammatory rheumatic diseases: The eye and rheumatoid arthritis, ankylosing spondylitis, psoriatic arthritis. Best Pract \& Res Clin Rheumatol [Internet]. 2016;30(5):802-25. Available from: http:// dx.doi.org/10.1016/j.berh.2016.10.007

6. Lee RWJ, Dick AD. Current concepts and future directions in the pathogenesis and treatment of non-infectious intraocular inflammation. Eye [Internet]. 2012;26(1):17-28. Available from: http://dx.doi.org/10.1038/eye.2011.255

7. Smith JR, Stempel AJ, Bharadwaj A, Appukuttan B. Involvement of $B$ cells in non-infectious uveitis. Clin Transl Immunology [Internet]. 2016;5(2):e63. Available from: http:// dx.doi.org/10.1038/cti.2016.2 (c) (i) (2) Open Access This article is licensed under a (c) BY NC SA Creative Commons Attribution-NonCommercialShareAlike 4.0 International License, which permits use, share - copy and redistribute the material in any medium or format, adapt - remix, transform, and build upon the material, as long as you give appropriate credit, provide a link to the license, and indicate if changes were made. You may do so in any reasonable manner, but not in any way that suggests the licensor endorses you or your use. You may not use the material for commercial purposes. If you remix, transform, or build upon the material, you must distribute your contributions under the same license as the original. You may not apply legal terms or technological measures that legally restrict others from doing anything the license permits. The images or other third party material in this article are included in the article's Creative Commons license, unless indicated otherwise in a credit line to the material. If material is not included in the article's Creative Commons license and your intended use is not permitted by statutory regulation or exceeds the permitted use, you will need to obtain permission directly from the copyright holder. To view a copy of this license, visit https://creativecommons.org/licenses/by-nc-sa/4.0/. 